\title{
The Department of Surgery of the Université de Montréal, 70th anniversary
}

\author{
Michel Carrier, MD, MBA \\ Louis Guertin, MD \\ Jean- François Latulipe, MD \\ Michel Pellerin, MD \\ Stephen Parent, MD \\ André Roy, MD \\ Louis P. Perrault, MD, PhD
}

Accepted Aug. 31, 2020

\section{Correspondence to:}

M. Carrier

Department of Cardiac Surgery

Montreal Heart Institute

5000 Belanger St.

Montreal QC H1T 1C8

michel.carrier@icm-mhi.org

DOI: $10.1503 /$ cjs. 017720

\section{SUMmARY}

The Department of Surgery of the Université de Montréal was officially chartered in 1961, but the structure had been in place since since 1951. The department grew as a fusion of hospital-based surgery training programs from the largest French-speaking hospitals in Montreal. Currently 448 professors (135 women and 313 men) teach in the department. The research activity, both clinical and applied, is in strong progression. The Department of Surgery is the largest French and bilingual training centre in Canada and North America. In 2021 the department will celebrate its 70th anniversary. As members, we should be proud of the work achieved by our predecessors and by the current rank of professors, teachers and researchers. The department strives to promote the essential role of and highlight the rewards and benefits of academic surgery.

\section{A}

lthough the department of surgery of the Université de Montréal was officially chartered in 1961, it had been in place since 1951, under the leadership of Dr. Jacques Bruneau and Dr. Edouard Desjardins. ${ }^{1}$ The department grew as a fusion of hospital-based surgery training programs from the 4 largest French-speaking hospitals in Montreal: Hotel-Dieu de Montréal, Notre-Dame, Saint-Luc, and Sainte-Justine. The Maisonneuve-Rosemont and Sacré-Coeur hospitals as well as the Montreal Heart Institute joined the department a few years later. The first director officially appointed by the Université de Montréal was Dr. Marcel Lamoureux in 1961.

Specialty programs were in place and recruiting students by 1970 under the new director of the department, Dr. Maurice Parent. Research activities were coordinated by a group of driven surgeons, including Dr. Conrad Pelletier (cardiac surgery), Dr. Jules Hardy (neurosurgery), Dr. Pierre Daloze (transplantation) and Dr. Claude Chartrand (pediatric cardiac surgery). All of them published extensively, recruited students and obtained external research grants. Dr. Jacques Desmarchais was also recruited for his expertise in medical pedagogy. Dr. Hervé Blanchard became the first person responsible for the admission committee of all surgical residency programs, and Dr. Denis Bourbeau ${ }^{2}$ in 1981 became the first director of the so-called "Tronc Commun" representing the first 2 years of surgical training for all residents.

\section{NoWADAYS}

Before 2008, the surgical services functioned as separate units, and there was no university structure allowing them to join forces. It was only in 2008, at the initiative of Dr. Luc Valiquette, that surgical divisions in each specialty were created. This allowed better coordination of future teacher recruitment, planning of research, and education activities across all university medical centres. Nowadays, the network of hospitals affiliated with Université de Montréal are the Centre Hospitalier de l'Université de Montréal (CHUM), Sainte-Justine, Maisonneuve-Rosemont and Sacré-Coeur hospitals and the Montreal Heart Institute. 


\section{TEACHING ACTIVITIES FROM THE BEgINNING}

Currently 448 professors ( 135 women and 313 men) teach in the department, including 184 clinical lecturers focusing specifically on undergraduate training, 121 assistant clinical professors, 77 associate clinical professors, 18 full clinical professors focused on both undergraduate and posgraduate clinical training, and 39 professors within tenure track careers, mostly at the level of full professor, who assume leadership in research, teaching and administrative work in the department.

The usual number of postgraduate students admitted into our residency programs ranges between 20 and 30 per year according to variation in government policies. We have experienced a significant decrease in numbers over the last 5 years (Fig. 1). Currently we have 88 residents in training among our specialty programs.

Over the last few years, more than 10 subspecialty fellowship programs officially recognized by the university or by the Royal College have been added. We have been successful in attracting French- and English-speaking American, European, North African, South American and Asian trainees.

\section{Research Activities}

The research activity, both clinical and applied, is clearly in strong progression. In the last few years, the output of publications in scientific journals has risen rapidly, reflecting the vitality of researchers, the volume of clinical activities, and the contribution of all our students (Fig. 2). During the same period, external grant funding has progressed, and the number of endowed research chairs (15 chairs) and special funds (12 funds) have increased to develop and sustain clinical and basic science research activities in the department. Eight of our professors are clinicianresearcher scholars recognized and supported by the Fonds de Recherche en santé du Québec.

Furthermore, 18 residents from our different surgery programs enrolled in the Royal College of Physicians and Surgeons of Canada's Clinician Investigator Program in the last few years.

\section{IMPORTANCE OF THE DEPARTMENT AT THE COMMUNITY LEVEL}

The department of surgery remains a leader in research, technical development and clinical activities in Quebec and in Canadian communities (Table 1). Not only have several "surgical firsts" been performed by our groups, but the impact of our trainees in surgical practice across Quebec, Canada and worldwide is also largely reflective of the dynamism of our divisions and subspecialty groups and research teams. ${ }^{3}$

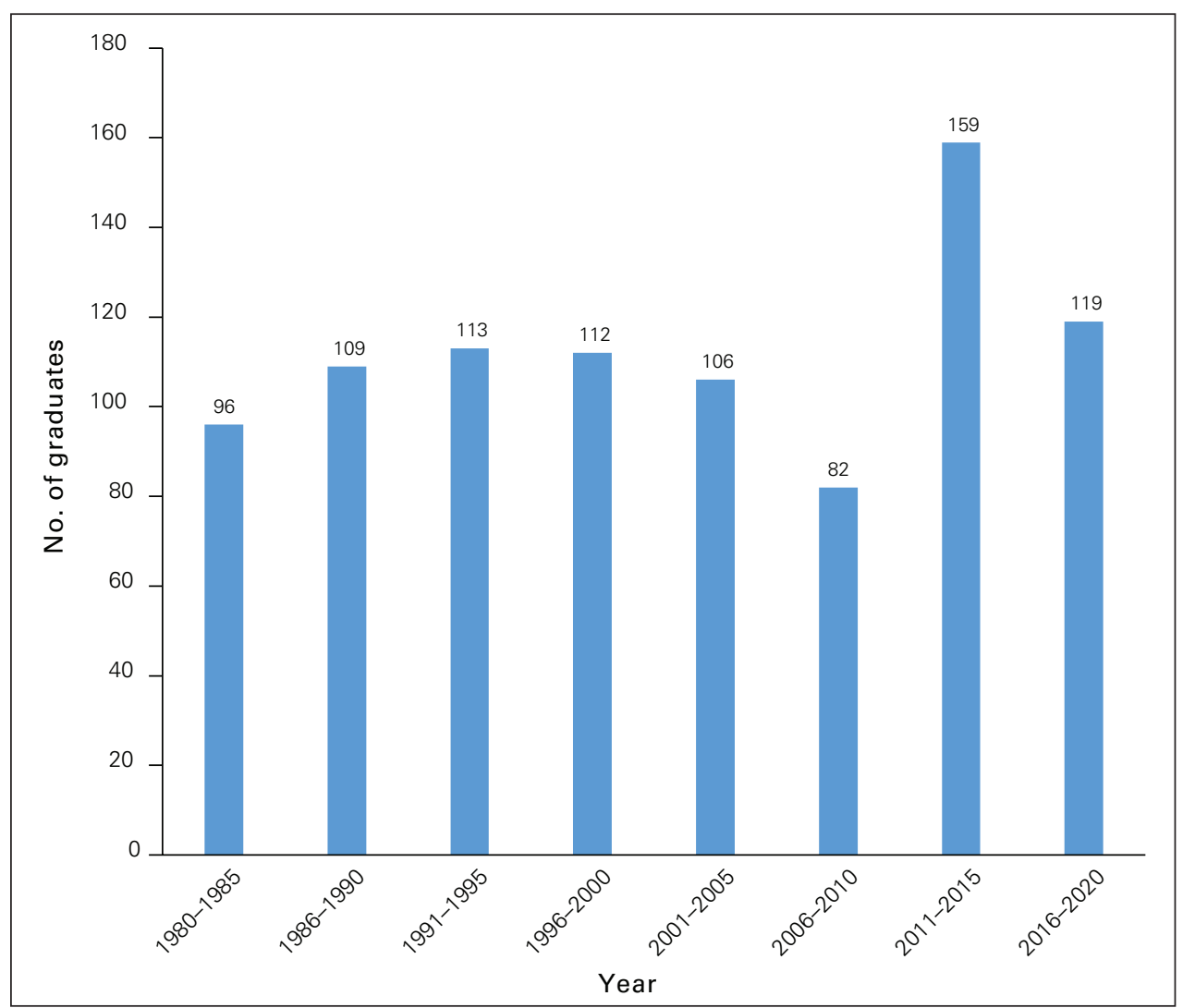

Fig. 1. Number of graduate students in the residency programs of the Department of Surgery, Université de Montréal. 


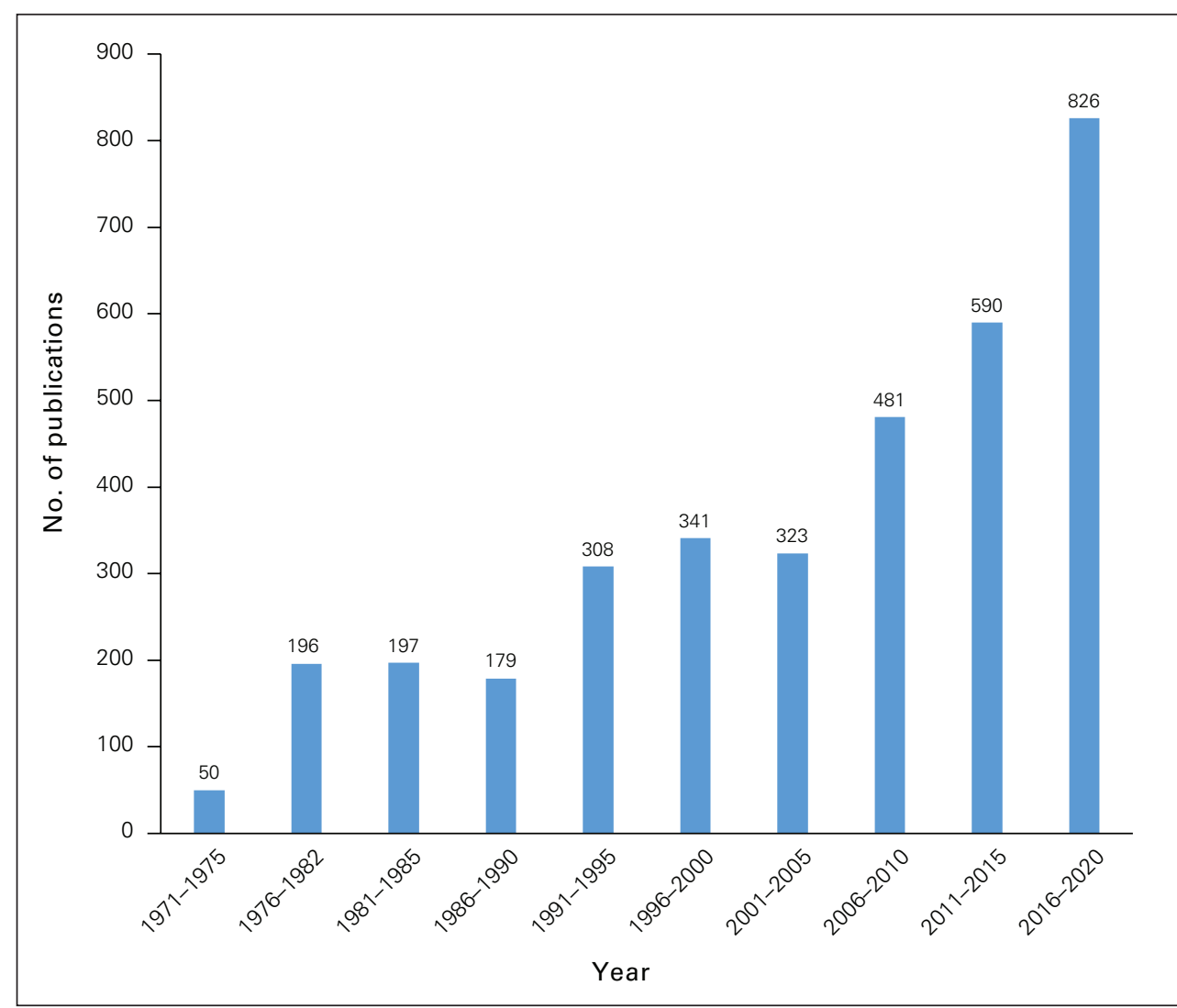

Fig. 2. Number of publications generated by the Department of Surgery, Université de Montréal.
Canada and North America. This must be recognized as a significant international asset and should continue to be valued and supported by the Canadian community.

\section{Conclusion}

The year 2021 will mark the 70 th anniversary of our department. As members, we should be proud of the work achieved by our predecessors and by the current rank of professors, teachers and researchers. As Quebecers, we should be proud of the quality of surgical practice offered across our community. As Canadians, we should be equally proud, not only of the academic contribution of the department, but also of its cultural, ethnic and linguistic diversity, which embodies our national values. The department strives to promote the essential role and highlight the rewards and benefits of academic surgery.

Affiliations: From the Department of Cardiac Surgery, Montreal Heart Institute, Division of Cardiac Surgery, Université de Montréal, Montreal, Que. (Carrier, Pellerin, Perrault); Faculty of medicine, Divisions of Head an Neck Surgery, General Surgery and Orthopedic Surgery, Université de Montréal, Montreal, Que. (Guertin, Latulipe, Parent, Roy).

Competing interests: Michel Carrier is an associate editor of CFS; he was not involved in the review or decision to accept this manuscript for publication. No other competing interests were declared.

Contributions: All authors contributed substantially to the conception, writing and revision of this article and approved the final version for publication.

\section{References}

1. Parent M. Histoire du Département de chirurgie. Infomed 1993;16:8-11.

2. Rheault MJ. Histoire du Département de chirurgie de l'Université de Montréal. Université de Montréal; 2001 Aug. 27. Available: https:// chirurgie.umontreal.ca/department/historique/histoire-du-departement -de-chirurgie-de-luniversite-de-montreal/ (accessed 2020 Aug. 31).

3. Stone MJ. Pierre Grondin, Surgeon 1925-2006. The Globe and Mail 2006 Jan. 30. 